\title{
A Review on Research Self-Efficacy as an Optimistic Raise of Human Development
}

\author{
Vikram Sharma ${ }^{1}$, Dr. Kuldip Kaur Grewal ${ }^{2}$, Dr. Mohua Khosla ${ }^{3}$ \\ ${ }^{1}$ Research Scholar, CT University, Ludhiana. \\ ${ }^{2}$ Professor, Department of Education, School of Humanities and Physical Education, CT University, Ludhiana \\ ${ }^{3}$ Associate Professor, Malwa Central College of Education for women, Ludhiana.
}

\begin{abstract}
Research Self-efficacy indicates individuals' convictions about their capacity to act in various circumstances. It capacities as a staggered and diverse arrangement of convictions that impact how individuals feel, think, rouse itself, and carry on during different errands. Self-adequacy convictions are educated with established achievement, shocking practice, imaginable encounters, and public influence just as material and passionate states. Convictions are interceded with psychological, inspirational, full of feeling, and determination cycles to create real execution. Research Self-Efficacy improvement is firmly interwoven with an individual's encounters, skills, and formative assignments in various areas at various stages throughout everyday existence. Paper surveys about writing toward layout to explanation along with hypothetical construct of the develop initially formulated by (Bandura 1977). Illustration as of the investigations build to survey Research self efficacy, and advise optimistic youth improvement, review introduce the causation of the advancement of Research self-efficacy convictions differentiate the connection between Research self-Efficacy and young adult formative results. This review finishes up among techniques to upgrade Research self-efficacy in youth with recommendations for prospect examination bearings.
\end{abstract}

Keywords: Research Self-efficacy, Human Development, Optimistic.

\section{INTRODUCTION}

Since the 1970s, the social intellectual hypothesis proposed by Bandura has been quite possibly the most powerful speculations used to manage the comprehension of human conduct and the persuasive determinants of such conduct. The hypothesis advocates a subject of "triadic correspondence" which affirms that an individual's conduct is continually under the equal impact of the climate and individual discernments. At the point when applied with regards to young adult turn of events, like scholastic execution, this hypothesis proposes that a juvenile's scholarly presentation is impacted by how this present juvenile's convictions are influenced by the help given by their critical others, including guardians, instructors, and friends. (Bandura and Ramachaudran 1994)contends that self-efficacy is the most significant factor influencing an individual's comprehension, and his declaration has promoted self-viability concentrates since the 1990s.

The accompanying segments plan to introduce discoveries and perceptions from a survey of the writing on the definition, evaluation, hypothetical conceptualizations, young adult advancement results, and advancement systems of self-adequacy, with explicit reference to optimistic youth improvement. Recognized examination holes and ideas for future exploration will likewise be introduced.

\section{RESEARCH SELF-EFFICACY}

Research Self-Efficacy evaluation is required for understanding the nature and strength of convictions that impact execution. Quantitative and subjective evaluation measures and procedures have been concocted to survey general self-efficacy, just as sources and cycles of self-adequacy. Self-adequacy is best surveyed inside the thought of context oriented elements to recognize whether it plays an intervening, directing, or other job in a social execution. On account of optional school understudies' turn of events, logical components like sex, nationality, scholarly capacity, and scholastic area ought to be need concerns.

(Usher and Pajares 2008)depicted and fundamentally investigated both quantitative and subjective intends to evaluate wellsprings of self-adequacy in school. They found that scales utilizing Likert-type things have been made to evaluate sources like dominance experience, vicarious experience, social influences, and physiological state. These sources have changed psychometric properties when tried with build or illustrative factor investigation, or develop legitimacy and interior dependability. Notwithstanding, they likewise tracked down that the unwavering quality measures on vicarious encounters have reliably been quite low, and more examinations are expected to reinforce such measures. 


\section{International Advanced Research Journal in Science, Engineering and Technology}

Vol. 8, Issue 6, June 2021

\section{DOI: $10.17148 / I A R J S E T .2021 .8617$}

(Usher and Pajares 2008) additionally recognized some subjective strategies that can be utilized to evaluate selfadequacy and wellsprings of Research self-efficacy under various individual, social, situational, and transient conditions. Techniques incorporate grounded hypothesis, ethnography, study hall perceptions, contextual investigations, interviews, self-give an account of reviewed explanations behind self-efficacy decisions, and selfrelegated loads of self-viability in regards to scholastic execution. It was tracked down that the semi structured meet is generally helpful for catching both the level headed and emotional parts of self-adequacy convictions, and the nature and cycles of the impact of these convictions on execution.

Subjective strategies are especially valuable for considering situations where people actually harbor debilitating selfquestions despite the fact that they have been perceived to have above and beyond skill in playing out the assignment being referred to. Along these lines, it is essential to blend the appraisal of such sources with an evaluation of mental cycles like inspiration, feeling the board, procedures in task determination, and critical thinking cleverness. Considering the way that self-adequacy is unpredictable and setting explicit, there is a requirement for analysts to create careful measures that viably evaluate the multidimensionality of the speculated sources and cycles of selfefficacy, along with the qualities and dynamic collaborations of these sources and cycles.

While apparently incredible progression has been accomplished in the evaluation of Research self-efficacy, it must be noticed that creating some very undertaking explicit appraisal measures in the changing existence where youngsters learn and live can be a tedious and surprisingly interminable pursuit. It appears to be that while finding some kind of harmony among consensus and particularity, future exploration should in any case attempt to discover the center components of self-efficacy convictions that are delicate to mediation and that can be dependably and truly estimated and looked at for changes. In Hong Kong, endeavors to build up a self-adequacy scale for Chinese junior optional school understudies have been made, and the psychometric properties of that scale are good. The scale comprises of 7 things including articulations that are to be replied in a 6-point scale of Likert design. It is as yet a somewhat broad Research self-efficacy scale for adolescents, yet it is a major advance forward in contriving approaches to quantify culture-explicit self-efficacy in youngsters in China. This is significant as China is affecting the world both as far as the size of its populace and its asset possibilities. There is additionally proof appearance that since Chinese guardian's kids actually esteem scholarly accomplishment as the main facilitator for up friendly versatility, they state such a lot of worry on scholastic execution that regularly high scholarly achievers actually experience the ill effects of low scholastic self-viability.

Every one of these things propose that for Chinese, notwithstanding an overall self-efficacy scale, different scales zeroing in on more explicit areas like scholastic, social, sports, moral, data innovation the executives, and social administrations additionally should be created to completely address the various parts of youth gifts and execution and to yield data on potential methods for intercession.

\section{Literature Review on Self-Efficacy Theories}

(Klassen and Usher 2010)Research educated hypothetical plans regarding Research self-efficacy drew from learning, intellectual, and social psychological speculations and had the option to reveal insight into the nature, sources, and mental cycles engaged with the development of self-viability convictions. Learning speculations endeavoring to clarify the development of conduct originally centered around molding, and afterward on the outcomes of conduct. Intellectual hypotheses of learning brought insight into the conduct age measure and underscored the thought of gains or misfortunes coming about because of playing out the said conduct as critical central consideration.

Research along these line shows that individuals' Research self-efficacy convictions about their capacities and about the results of their endeavors are especially prescient of real conduct, similar to scholastic execution and surprisingly professional decisions. Self-efficacy is likewise "related with key persuasive builds like causal attributions, self-idea, hopefulness, accomplishment objective direction, scholastic assistance chasing, nervousness, and worth" and is in this way the main develop of the social intellectual hypothesis(Usher and Pajares 2008).

The hypothesis states that self-viability convictions work through the four significant mental cycles recorded beneath to create real execution.

(a) Cognitive cycles: these incorporate self-evaluation of abilities, abilities, and assets; objective choice; development of achievement and disappointment situations in the objective achievement measures; age and choice of critical thinking alternatives; supporting the vital consideration and working for task fruition.

(b) Motivational cycles: self-adequacy convictions influence one's self-guideline of inspiration. Three intellectual inspirations, in particular, "attribution," "worth of anticipated results," and "clearness and worth of objectives" have been recognized as being impacted without anyone else adequacy convictions.

(c) Affective cycles: an individual's self-view of adapting capacities influences the individual's excitement edge and their resilience of passionate dangers like uneasiness and wretchedness(Ehrenberg, Cox et al. 1991). Indeed, even the interaction and result of danger the executives can be influenced by methods like controlling symbolism to change uneasiness manifestations while experiencing stressors(Munroe-Chandler, Hall et al. 2008). 


\section{International Advanced Research Journal in Science, Engineering and Technology}

Vol. 8, Issue 6, June 2021

\section{DOI: $10.17148 /$ IARJSET.2021.8617}

(d) Selection cycles: choices on decision of home, vocation, family arrangement, and even utilization of time can straightforwardly impact an individual's working. To achieve the results they are keen on, individuals with high selfadequacy are more proactive in choosing and establishing a physical and social climate that coordinates with their apparent capacities and assets. Their odds of effective objective fulfillment and self-improvement are additionally boosted all the while.

As indicated by (Bandura, Freeman et al. 1999) and(Maddux and Gosselin 2012), Research self-efficacy convictions framed through the above measures are not static. They are continually educated, empowered, or drained through in any event five recognizable essential sources that are influenced by an individual's translations of previous and current encounters.

(1) Vicarious experience: perception of fruitful assignment execution by friendly models (like guardians and educators), and by those whose capacities are like oneself (like companions for youngsters), creates a solid selfappreciation viability. Viable dominance and adapting models, like guardians, educators, or companions who adapt ably to challenges, can exhibit and invigorate the acquiring of abilities and methodologies(Schunk and Zimmerman 2007). These models can likewise advance the status of youngsters to set thoughts in motion, consequently making more possibilities for progress that will additionally upgrade self-viability.

(2) (Fan and Williams 2010)Social influence: persuading verbal influence given by critical others, similar to guardians and educators, can upgrade a youngster's self-viability, given that the adolescent truly has the capacities being referred to. Inability to finish an undertaking that depended on bogus assumptions can accomplish more to harm self-viability convictions than to develop them. Effective social influence ought to remember control of all factors for the triadic correspondence measure: development of the conduct collection through abilities preparing and natural control to work with fruitful execution, just as persuading influence regarding the allure of the result. As of late, there has been an arising pattern to present develop and fruitful grown-ups from the local area to fill in as tutors for youngsters to extend the social capital of youngsters past family and school limits. The job demonstrating and direction of these coaches ought to give valuable self-viability sources to youngsters.

(3) Imaginal encounters: imaginal practice of effective or fruitless execution, be it intentional or while ruminating, can improve adapting methodology and upgrade self-efficacy(Maddux and Gosselin 2012). Models incorporate creative mind based intercessions, for example, efficient desensitization, and undercover displaying. In advancing youth self-viability, the utilization of experiential activities and pretending in abilities practice has been discovered to be useful in extending youth experience and planning.

Cautious agreement and control of the above mental cycles and sources that impact the development and working of self-adequacy convictions ought to make promising roads for the advancement of self-viability. With regards to optimistic youth improvement, (Usher and Pajares 2008) basically checked on the writing on the wellsprings of selfviability in school and proposed headings for exploration and upgrade systems.

In particular, Usher and Pajares recognized an invitational methodology that recommends that the convictions individuals create about themselves and about others together structure the perceptual focal points through which individuals see the world and like new encounters. The messages that individuals get and send are crucial in making self-adequacy convictions. Bandura additionally expressed that the interaction among the self-viability sources can be added substance, relative, multiplicative, or configurative.

While Bandura almost solely underscores the causal significance of self-efficacy convictions in affecting last conduct, there is likewise expanding proof causing because of notice the significance of result anticipations in delivering conduct. A portion of the new applications on youngsters incorporate hope concentrates on liberal conduct, such as betting, smoking(Bektas, Ozturk et al. 2010), and digital habit(Lin, Ko et al. 2008). There ought to likewise be more conversation on the most proficient method to oversee potential bungles between self-adequacy and the information and abilities vital for task execution, and how to assist adolescents with low skill and lacking work mentalities yet high self-viability development utilitarian fitness and demeanor. More examinations are as yet expected to build up the particular job of every self-adequacy source and measure and the job they play in advising and improving real execution.

As of late, self-adequacy examines have been concentrating on the ecological variable, and to talking about individual versus aggregate self-efficacy. In a setting like optional schools where teenagers are continually in close communication with their companions and educators, exploration ought to go past singular viability contemplates and analyze the aggregate adequacy of the entire class, subgroups in the class, instructors and understudies as subgroups in a school, or one school versus others in open rivalries with different schools(Klassen and Usher 2010). As teenagers are still chiefly affected by families and schools in their turn of events, endeavors to conjecture and upgrade juvenile turn of events and execution ought to likewise focus on the efficacy.

\section{Literature Review on Research Self-Efficacy and Optimistic Raise of Human Developmental Outcomes}

(Pajares 1996)inspected more than 20 years of Research self-efficacy research and recognized two primary lines of study: 


\section{International Advanced Research Journal in Science, Engineering and Technology}

Vol. 8, Issue 6, June 2021

\section{DOI: $10.17148 /$ IARJSET.2021.8617}

(a) Interfacing self-adequacy convictions with school major and professional decisions.

(b) Reviewing the associations among self-efficacy, other mental builds, and scholastic execution.

There are various exploration contemplates showing that self-viability convictions help decide both assignment execution and adapting. On account of youths,(Pajares 2006) showed that self-adequacy predicts scholastic zones and levels, while (Brown and Lent 2006) recognized that self-viability predicts understudies' school major and profession decisions. In their 2008 survey of the writing since 1977 on the wellsprings of self-efficacy in school, (Usher and Pajares 2008) saw that self-adequacy is "related with key inspirational develops like causal attributions, self-idea, confidence, accomplishment objective direction, scholarly assistance chasing, tension, and worth". Self-viability is likewise associated with self-managed getting the hang of, remembering understudies' choice to remain for school, and scholarly tarrying(Klassen, Krawchuk et al. 2008).

Beside scholastic execution and study style, self-efficacy likewise affects young people's presentation in extracurricular exercises like soccer. An audit of two school mediation projects planning to advance understudies' Research self-efficacy and school psychological wellness in Germany tracked down that individualized errand requests and explicit educator criticism upgrade understudy self-efficacy, while social self-efficacy is encouraged through a optimistic class environment with common help among understudies(Jerusalem and Hessling 2009), and when instructors are touchy to the individual requirements of the understudies. The understudies who completed the ventures announced improved persuasive directions, adapting to pressure, and struggle settling.

\section{Advancement of Research Self-Efficacy in Human Beings}

There is a lot of exploration proof showing that convenient and key development of optimistic Research self-efficacy in early immaturity is significant and conceivable. In 1998, Richard Catalano and his partners in the University of Washington evaluated 25 compelling "optimistic Youth Development Programs in the United States" and tracked down that every one of these projects incorporated a segment to advance self-efficacy(Catalano, Berglund et al. 2004). Famous topics incorporated the improvement of abilities, duty, strong connections, and having a place. There is additionally an expanded sign that the advancement systems must be age, sex, undertaking, and culture explicit to show the best outcomes, and utilizing self-adequacy assessment measures custom fitted for the errand to be dominated will likewise show the most clear intercession impact. These discoveries have educated instructing in Hong Kong and exploration showing their convenience is simply starting to develop. A portion of the systems found helpful for Chinese younger students were rivalries in vicarious learning for composing errands, and conveying individual and developmental evaluative criticism to encourage self-adequacy in English jargon securing(Chan and Lam 2010).

Beside work finished with singular youths, expanding consideration is being paid to develop aggregate Research selfefficacy(Klassen and Usher 2010). An entire class in an optional school, or a gathering in a group project, or even an entire school, can likewise be utilized as an aggregate unit, contingent upon whether it is a class, gathering, or schoolbased errand. Consideration of the confidence in viability, be it the group chief, an individual understudy, or the mindful instructor or mentor, is likewise discovered to be helpful in liking the full sources and elements of selfefficacy.

\section{CONCLUSION}

Thinking about the ebb and flow writing, and the survey of self-efficacy concentrates Usher and Pajares, just as the audit by Klassen and Usher on 244 articles from 65 diaries of self-viability considers, coming up next is suggested for future self-adequacy research, particularly where young adult optimistic advancement is concerned.

Refine the estimation of the self-viability sources: every one of the four named self-viability sources contrasts in nature, and they fluctuate as indicated by the errand and the setting being referred to, so that there ought to be source and undertaking explicit evaluations to identify any progressions with satisfactory affectability.

\section{REFERENCES}

[1]. Bandura, A. (1977). "Self-efficacy: toward a unifying theory of behavioral change." Psychological review, Vol 84, issue 2, P.No 191.

[2]. Bandura, A., et al. (1999). Self-efficacy: The exercise of control, Springer,Vol 15,P.No 158 to 166.

[3]. Bandura, A. and V. S. Ramachaudran (1994)."Encyclopedia of human behavior." New York: Academic Press, Volume 4, P.No 71 to 81.

[4]. Bektas, M., et al. (2010). "An approach to children's smoking behaviors using social cognitive learning theory." Asian Pac J Cancer Prev, Vol 11, issue 4, P.No 1143 to 1149 .

[5]. Brown, S. D. and R. W. Lent (2006). "Preparing adolescents to make career decisions: A social cognitive perspective."Adolescence and education, Vol 5, P.No 201 to 223.

[6]. Catalano, R. F., et al. (2004). "Positive youth development in the United States: Research findings on evaluations of positive youth development programs." The annals of the American academy of political and social science, Vol591, issue 1, P.No 98 to 124.

[7]. Chan, J. C. and S.-f. Lam (2010). "Effects of different evaluative feedback on students' self-efficacy in learning." Instructional Science, Vol38, issue 1, P.No37 to 58 .

[8]. Ehrenberg, M. F., et al. 1991. "The relationship between self-efficacy \& depression in adolescents." Adolescence, Vol 26, iss 102 , P.No. 361. 


\section{International Advanced Research Journal in Science, Engineering and Technology}

Vol. 8, Issue 6, June 2021

\section{DOI: $10.17148 /$ IARJSET.2021.8617}

[9]. Fan, W. and C. M. Williams (2010). "The effects of parental involvement on students' academic self-efficacy, engagement and intrinsic motivation." Educational Psychology, Vol 30, issue 1,P.No53 to 74.

[10]. Jerusalem, M. and J. K. Hessling (2009). "Mental health promotion in schools by strengthening self-efficacy."Health education.Vol 109, issue 4, P.No 210 to 218

[11]. Klassen, R. M., et al. (2008). "Academic procrastination of undergraduates: Low self-efficacy to self-regulate predicts higher levels of procrastination." Contemporary educational psychology,Vol33, issue 4, P.No 915 to 931.

[12]. Klassen, R. M. and E. L. Usher (2010). "Self-efficacy in educational settings: Recent research and emerging directions." The decade ahead: Theoretical perspectives on motivation and achievement, Vol 16, P.No. 1 to 33.

[13]. Lin, M.-P., et al. (2008). "The role of positive/negative outcome expectancy and refusal self-efficacy of Internet use on Internet addiction among college students in Taiwan." CyberPsychology\& Behavior, Vol 11, issue 4, P.No 451 to 457.

[14]. Maddux, J. E. and J. T. Gosselin (2012). Self-efficacy, The Guilford Press, P.No 198 to 224.

[15]. Munroe-Chandler, K., et al. (2008)."Playing with confidence: The relationship between imagery use and self-confidence and self-efficacy in youth soccer players." Journal of sports sciences,Vol26, issue 14, P.No 1539 to 1546.

[16]. Pajares, F. (1996). "Self-efficacy beliefs in academic settings." Review of educational research,Vol66. issue 4, P.No 543 to 578.

[17]. Pajares, F. (2006). "Self-efficacy during childhood and adolescence."Self-efficacy beliefs of adolescents, Vol 5, P.No 339 to 367.

[18]. Schunk, D. H. and B. J. Zimmerman (2007). "Influencing children's self-efficacy and self-regulation of reading and writing through modeling." Reading \& writing quarterly, Vol 23, issue 1, P.No 7 to 25.

[19]. Usher, E. L. and F. Pajares (2008). "Sources of self-efficacy in school: Critical review of the literature and future directions." Review of educational research, Vol 78, issue 4, P.No 751 to 796 . 